\title{
DIFFERENCES IN HEART TRANSPLANT PHYSIOLOGY ACCORDING TO SURGICAL TECHNIQUE
}

Jesus Peteiro, $\mathrm{MD}^{\mathrm{a}}$

Francisco Redondo, $\mathrm{MD}^{\mathrm{a}}$

Ramon Calviño, $\mathrm{MD}^{\mathrm{a}}$

Jose Cuenca, $\mathrm{MD}^{\mathrm{b}}$

Gonzalo Pradas, $\mathrm{MD}^{\mathrm{b}}$

Alfonso Castro Beiras, $\mathrm{MD}^{\mathrm{a}}$
A new cardiac transplantation technique that preserves the shape of the left atrium and leaves the right atrium intact has been introduced. To compare the new and the standard techniques, we studied cardiac physiology with Doppler echocardiography and catheterization in 26 patients who underwent operation with the standard technique (group A) and 11 who underwent operation with the new technique (group B). Right atrial dimensions were significantly lower in group $B$ (right atrial area index $8.4 \pm 1.5$ vs $14.5 \pm 1.9$ $\mathrm{cm}^{2} / \mathrm{m}^{2}, p<0.001$ ), whereas left atrial dimensions were slightly lower (left atrial area index $10.8 \pm 2.0$ vs $16.4 \pm 7.0 \mathrm{~cm}^{2} / \mathrm{m}^{2}, p=0.07$ ). Right atrial contraction, as reflected by peak late tricuspid velocity, was greater in group $B$ $(37 \pm 15$ vs $30 \pm 10 \mathrm{~cm} / \mathrm{sec}, p<0.05)$. The subsequent systolic vena caval flow-velocity integral was also greater in group $B$ at all respiratory phases (inspiration $10.0 \pm 4.0$ vs $5.2 \pm 4.0 \mathrm{~cm}, p<0.001$; expiration $4.8 \pm 1.9$ vs 2.9 $\pm 1.4 \mathrm{~cm}, p<0.001$; apnea $5.3 \pm 2.0$ vs $2.9 \pm 1.9 \mathrm{~cm}, p<0.001$ ) suggesting better atrial relaxation. Filling pressures on the right side of the heart were lower in group B (mean right atrial pressure $5.5 \pm 2.4$ vs $6.6 \pm 2.8 \mathrm{~mm} \mathrm{Hg}, p=$ 0.1 ; right atrial A wave $6.0 \pm 3.1$ vs $8.3 \pm 3.2 \mathrm{~mm} \mathrm{Hg}, p<0.01$; right atrial V wave $6.8 \pm 3.1$ vs $9.2 \pm 3.2 \mathrm{~mm} \mathrm{Hg}, p<0.01$; right ventricular end-diastolic pressure $5.6 \pm 3.2$ vs $7.3 \pm 2.9 \mathrm{~mm} \mathrm{Hg}, p<0.05$ ); however, no significant differences were found in left ventricular end-diastolic pressure or cardiac index. We conclude that patients undergoing the new technique exhibit cardiac physiologic improvements. Follow-up study is indicated to ascertain whether this finding implies improved long-term prognosis. (J Thorac Cardiovasc Surg 1996;112:584-9)
0 rthotopic cardiac transplantation is usually performed by connecting atrial cuffs. ${ }^{1-2}$ Recently, a surgical technique that preserves the shape of the left atrium and leaves the right atrium intact through suturing of the recipient and donor caval veins was introduced. ${ }^{3}$ Although recent studies have demonstrated a lowered prevalence of arrhythmias $^{4,5}$ and less tricuspid and mitral regurgitation, ${ }^{4-6}$ hemodynamic studies comparing the two techniques are few. ${ }^{3-5}$ To better understand physiology after heart transplantation, we prospectively studied, by Doppler echocardiography and catheter-

From the Departments of Cardiology ${ }^{a}$ and Cardiovascular Surgery, ${ }^{b}$ Hospital Juan Canalejo, La Coruña, Spain.

Received for publication July 13, 1995; revisions requested Sept. 11, 1995; revisions received Dec. 21, 1995; accepted for publication Feb. 23, 1996.

Address for reprints: Jesus Peteiro, MD, P/Ronda 5-4 $4^{\circ}$ izda, 15011-A Coruña, Spain

Copyright (C) 1996 by Mosby-Year Book, Inc.

$0022-5223 / 96 \$ 5.00+0 \quad \mathbf{1 2 / 1 / 7 3 2 3 8}$ ization, 26 patients who underwent transplantation by the standard technique (group A) and 11 who underwent transplantation by the new technique (group B).

\section{Methods}

Studies and patients. We performed 122 consecutive Doppler echocardiographic and catheterization studies on the same day as endomyocardial biopsy. Seventy-three studies were performed on 27 group A patients and 49 studies were performed on 11 group B patients.

All studies were performed at least 3 weeks after transplantation. Study patients with nonsinus rhythm (two studies on one group A patient), more than mild pericardial effusion (one study on one group $B$ patient), more than mild tricuspid regurgitation (five studies on four group A patients), or rejection greater than 2 according to the Billingham scale (37 rejection biopsies [ $>$ grade 2], 19 in eight group A patients and 18 in 10 group B patients) were excluded from analysis.

We therefore present the results of 47 Doppler echocardiographic and right heart catheterization studies performed on 26 group A patients (1.8 studies/patient) and 30 such studies performed on 11 group B patients $(2.7$ studies/patient). Left heart catheterization was also per- 
Table I. Patient characteristics

\begin{tabular}{lccccc}
\hline & \multicolumn{2}{c}{ Group A $(n=26)$} & & Group B $(n=11)$ \\
\cline { 2 - 3 } & Mean & Range & & Mean & Range \\
\hline Age (yr) & $55 \pm 9$ & $28-65$ & $49 \pm 10$ & $28-63$ \\
Body surface area $\left(\mathrm{m}^{2}\right)$ & $182 \pm 15$ & $155-207$ & $183 \pm 18$ & $158-213$ \\
$\begin{array}{c}\text { Time of studies since } \\
\quad \text { transplantation (wk) }\end{array}$ & $23 \pm 12$ & $3-46$ & $17 \pm 11$ & $3-43$ \\
$\begin{array}{l}\text { Ischemic time (min) } \\
\text { Rejection episodes }\end{array}$ & $145 \pm 66$ & $32-284$ & $122 \pm 55$ & $46-200$ \\
$\quad 2.0 \pm 2.0$ & $0-6$ & $2.0 \pm 1.6$ & $1-5$
\end{tabular}

formed on 10 group A and 10 group B patients. All patients were taking standard doses of cyclosporine, azathioprine, and prednisone. Informed consent was obtained from each patient.

Doppler echocardiography. M-mode, two-dimensional, and pulsed Doppler studies were obtained with a Toshiba Sonolayer SSH-160A system with a $3.5 \mathrm{MHz}$ phased-array transducer (Toshiba, Tustin, Calif.). Echocardiographic $\mathrm{M}$-mode measurements were obtained according to the criteria of the American Society of Echocardiography. ${ }^{8}$ The tricuspid ring systolic displacement, a validated parameter that reflects right ventricular ejection fraction, ${ }^{9}$ was measured by $\mathrm{M}$-mode echocardiography from the apical four-chamber or the right parasternal long-axis view. The maximal reproducible value obtained at the lateral level, in a single plane, was considered. Left and right atrial measurements were obtained by two-dimensional echocardiography from the apical four-chamber view and included anteroposterior end-systolic left and right atrial dimensions and end-systolic left and right atrial areas.

Pulsed Doppler transmitral and transtricuspid flows were recorded from the apical four-chamber view. The sample volume was placed between the leaflets, guided by color-flow imaging. Recordings in which the recipient $\mathrm{P}$ wave occurred in early diastole or late systole were not used. ${ }^{10-11}$

At the mitral level, we measured peak early and late velocities, early wave deceleration time, and left ventricular isovolumic relaxation time. Left ventricular isovolumic relaxation time was obtained by placing the sample volume between the left ventricular inflow and outflow, as described elsewhere. ${ }^{12}$ Three reproducible recordings were measured on-line.

At tricuspid level, we measured peak early and late velocities. Three reproducible end-expiratory measurements were assessed on-line.

Right ventricular isovolumic relaxation time was obtained by subtracting pulmonary flow ejection time, as detected by pulsed Doppler at the pulmonary valve, from the tricuspid regurgitation signal time, as detected by continuous Doppler. We obtained 10 heart rate-matched on-line pulsed and continuous Doppler measurements to reduce dependence on respiratory variation.

Superior vena caval flow was recorded with the patient in the supine position. The transducer was positioned in the right supraclavicular fossa, and the sample volume was placed as deep as possible in the vena cava where an
Table II. Parameters calculated by Doppler echocardiography and tricuspid ring systolic movement for all study patients

\begin{tabular}{lcc}
\hline & Group A & Group B \\
\hline $\begin{array}{l}\text { Heart rate } \\
\text { (beats/min) }\end{array}$ & $85 \pm 11$ & $89 \pm 8$ \\
Systolic blood & & \\
$\quad$ pressure (mm Hg) & $136 \pm 13$ & $131 \pm 10$ \\
Diastolic blood & & \\
$\quad$ pressure (mm Hg) & $85 \pm 9$ & $80 \pm 11$ \\
LVEDD (cm) & $4.6 \pm 0.5$ & $4.5 \pm 0.3$ \\
IMV (gm/m $\left.{ }^{2}\right)$ & $129 \pm 39$ & $125 \pm 31$ \\
ESS (mm Hg) & $164 \pm 37$ & $155 \pm 33$ \\
FS (\%) & $27 \pm 6$ & $28 \pm 6$ \\
SPP (mm Hg) & $37 \pm 7$ & $35 \pm 7$ \\
CI (L. min & \\
Tricuspid ring & $2.8 \pm 0.5$ & $2.9 \pm 0.6$ \\
movement $(m m)$ & $13.5 \pm 3.2$ & $13.8 \pm 2.8$ \\
& &
\end{tabular}

$L V E D D$, Left ventricle end-diastolic diameter; $I M V$, left ventricle mass index; $E S S$, left ventricle end-systolic stress; $F S$, left ventricle fractional shortening; $S P P$, systolic pulmonary pressure; $C I$, cardiac index.

adequate color Doppler signal was seen. Vena caval Doppler flow measurements were forward peak systolic and diastolic velocities and forward systolic and diastolic flow-velocity integrals. Recordings were taken at inspiration, expiration, and midexpiratory apnea. Systolic pulmonary artery pressure was obtained by deriving maximal transtricuspid systolic velocity. ${ }^{13}$ Cardiac output was assessed by combining left ventricular outflow tract dimension, heart rate, and left ventricular outflow tract flowvelocity integral measurements. ${ }^{14}$ Blood pressure was recorded at the end of each study.

Catheterization study. A percutaneous femoral or jugular approach was used for catheterization. Right and left heart pressures were measured with fluid-filled $7 \mathrm{~F}$ or $8 \mathrm{~F}$ catheters. Cardiac output was determined by thermodilution.

Statistical analysis. Data are expressed as mean ( \pm standard deviation). Student $t$ test was used for comparison of groups $\mathrm{A}$ and $\mathrm{B}$. Linear regression analysis was used when appropriate. A $p$ value lower than 0.05 was considered significant.

\section{Results}

Patient characteristics. There were no differences in patient characteristics between groups (Table I).

Hemodynamic parameters. Heart rate, blood pressure, left ventricular diastolic diameter, left ventricular stress, systolic pulmonary pressure, cardiac index and tricuspid ring systolic movement (Table II) were similar for both groups.

Left and right atrial dimensions. As expected, right atrial dimensions were significantly reduced in patients submitted to the new technique (group B), 

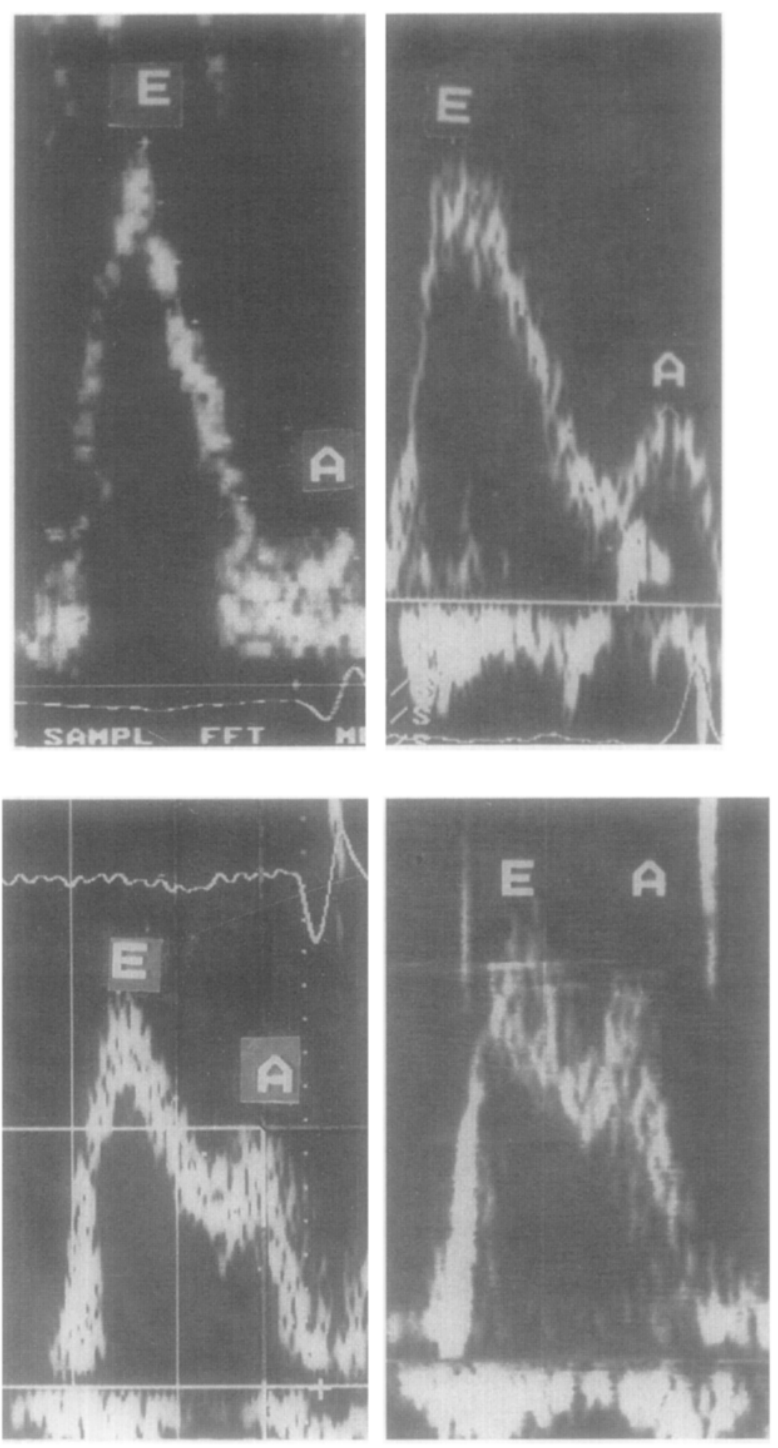

Fig. 1. Pulsed Doppler patterns at mitral (left) and tricuspid (right) levels in patients who underwent transplantation by standard (top) or new technique (bottom). Top, Patient who underwent transplantation by standard technique. Note reduced peak late velocities (A wave) at both mitral (left) and tricuspid (right) levels. Bottom, Patient who underwent transplantation by new technique. Peak late velocity is reduced at mitral level (left) but is normal at tricuspid level (right).

whereas left atrium dimensions were only slightly reduced (Table III).

Mitral and tricuspid valve Doppler indexes and left and right isovolumic relaxation times. Left and right isovolumic relaxation times were significantly decreased in group B ( $83 \pm 15$ vs $95 \pm 22 \mathrm{msec}, p<$ 0.01 and $56 \pm 22$ vs $86 \pm 27 \mathrm{msec}, p<0.001$,
Table III. Left and right atrial dimensions

\begin{tabular}{lccc}
\hline & Group $A$ & Group $B$ & $p$ \\
\hline Anteroposterior LA & $8.4 \pm 0.7$ & $6.9 \pm 1.2$ & $<0.05$ \\
$\quad$ dimension $(\mathrm{cm})$ & & & \\
LA area $\left(\mathrm{cm}^{2}\right)$ & $29.4 \pm 11.7$ & $20.2 \pm 4.5$ & 0.07 \\
LA area index $\left(\mathrm{cm}^{2} / \mathrm{m}^{2}\right)$ & $16.4 \pm 7.0$ & $10.8 \pm 2.0$ & 0.07 \\
Anteroposterior RA & $7.9 \pm 0.9$ & $5.9 \pm 1.5$ & $<0.05$ \\
$\quad$ dimension $(\mathrm{cm})$ & & & \\
RA area $\left(\mathrm{cm}^{2}\right)$ & $24.0 \pm 4.3$ & $16.0 \pm 3.9$ & $<0.01$ \\
RA area index & $14.5 \pm 1.9$ & $8.4 \pm 1.5$ & $<0.001$ \\
$\quad\left(\mathrm{~cm}^{2} / \mathrm{m}^{2}\right)$ & & &
\end{tabular}

Areas obtained in the four-chamber apical view. $L A$, Left atrium; $R A$, right atrium.

respectively). Peak early and late mitral flow velocities were similar for both groups $(78 \pm 17$ in group B vs $72 \pm 21 \mathrm{~cm} / \mathrm{sec}$ in group A, $p$ not significant, and $36 \pm 10$ in group $B$ vs $37 \pm 11 \mathrm{~cm} / \mathrm{sec}$ in group $\mathrm{A}, p$ not significant, respectively). Peak early tricuspid flow velocity was also similar for both groups (48 \pm 15 in group B vs $43 \pm 11 \mathrm{~cm} / \mathrm{sec}$ in group A, $p$ not significant), whereas peak late tricuspid flow velocity was increased in patients submitted to the new technique ( $37 \pm 15$ vs $30 \pm 10 \mathrm{~cm} / \mathrm{sec}, p<0.05$; Fig. 1).

Superior vena caval Doppler measurements. The pattern of superior vena caval flow in patients who underwent transplantation by the new technique (group B) was very similar to that of normal subjects ${ }^{15}$ and markedly different from that seen in patients who underwent transplantation by the standard technique (group A; Table IV).

Forward systolic and diastolic flows were similar in group B patients, whereas systolic flow was markedly decreased and diastolic flow was the major forward component in group A patients (Fig. 2). Peak systolic superior vena caval forward flow greater than diastolic superior vena caval forward flow was detected in four studies performed on four group A patients (8.5\% of group A studies) in different respiratory phases; at all phases in two studies, at expiration and apnea in one study, and only at expiration in one study. In contrast, this pattern was demonstrated in 19 studies performed on eight group B patients (63\% of group B studies; at all phases in six studies performed on four patients, and at any phase in 13 studies performed on another four patients).

Correlations. There was a weak but significant correlation between peak late tricuspid velocity and superior vena caval peak forward systolic velocity at inspiration, expiration, and midexpiratory apnea in 
Table IV. Superior vena caval peak forward flow velocities and flow-velocity integrals

\begin{tabular}{lccc}
\hline & Group A & Group $B$ & $p$ \\
\hline SFV insp (cm/sec) & $28 \pm 15$ & $41 \pm 12$ & $<0.001$ \\
SFV exp (cm/sec) & $19 \pm 6$ & $26 \pm 7$ & $<0.001$ \\
SFV apnea (cm/sec) & $18 \pm 9$ & $27 \pm 8$ & $<0.001$ \\
DFV insp (cm/sec) & $53 \pm 22$ & $47 \pm 14$ & NS \\
DFV exp (cm/sec) & $29 \pm 11$ & $27 \pm 12$ & NS \\
DFV apnea (cm/sec) & $31 \pm 15$ & $29 \pm 11$ & NS \\
Systolic FVI insp (cm) & $5.2 \pm 4.0$ & $10.0 \pm 4.0$ & $<0.001$ \\
Systolic FVI exp (cm) & $2.9 \pm 1.4$ & $4.8 \pm 1.9$ & $<0.001$ \\
Systolic FVI apnea (cm) & $2.9 \pm 1.9$ & $5.3 \pm 2.0$ & $<0.001$ \\
Diastolic FVI insp (cm) & $10.7 \pm 5.4$ & $9.4 \pm 2.9$ & NS \\
Diastolic FVI exp (cm) & $5.2 \pm 2.9$ & $4.6 \pm 2.8$ & NS \\
Diastolic FVI apnea (cm) & $6.0 \pm 3.7$ & $4.9 \pm 2.8$ & NS \\
SDV insp & $58 \pm 28$ & $93 \pm 30$ & $<0.001$ \\
SDV exp & $74 \pm 36$ & $113 \pm 72$ & $<0.05$ \\
SDV apnea & $67 \pm 38$ & $101 \pm 35$ & $<0.001$ \\
\hline
\end{tabular}

$S F V$, Peak forward systolic flow velocity; insp, inspiratory; exp, expiratory; $D F V$, peak forward diastolic flow velocity; $F V I$, forward flow-velocity integral; $S D V$, peak systolic to diastolic flow velocity relationship. $N S$, Not significant.

all patients $(r=0.31, p<0.01 ; r=0.30, p<0.01$; and $r=0.31, p<0.01$, respectively). Correlation between tricuspid ring systolic motion and superior vena caval peak forward systolic flow velocity was not found to be significant. We found no significant correlation between tricuspid ring systolic motion and time since transplantation $(r=-0.01, p$ not significant). Neither did we observe changes in superior vena caval forward flow pattern or right heart filling pressures during follow-up studies.

Catheterization variables. Right ventricular enddiastolic pressure and $\mathrm{A}$ and $\mathrm{V}$ right atrial pressure waves were significantly lower in group $B$ than in group A. Mean right atrial pressure was slightly lower in group B. There were no differences in left ventricular end-diastolic pressure and cardiac index between groups (Table V).

\section{Discussion}

In this study of patients after heart transplantation, we demonstrated the physiology of the right side of the heart to be extremely similar to that seen in healthy subjects in the group of patients who underwent transplantation by the new technique, in contrast with what is described as "restrictive physiology"16 seen in patients undergoing transplantation by the standard technique. Differences between the groups in physiology of the left side of the heart were less pronounced, probably as a result of the more similar left atrial size.

The most remarkable difference found was in the
Table V. Catheterization measurements

\begin{tabular}{lrrc}
\hline & Group $A$ & Group B & $p$ \\
\hline RA A wave $(\mathrm{mm} \mathrm{Hg})$ & $8.3 \pm 3.2$ & $6.0 \pm 3.1$ & $<0.01$ \\
RA V wave $(\mathrm{mm} \mathrm{Hg})$ & $9.2 \pm 3.2$ & $6.8 \pm 3.1$ & $<0.01$ \\
RA mean $(\mathrm{mm} \mathrm{Hg})$ & $6.6 \pm 2.8$ & $5.5 \pm 2.4$ & 0.1 \\
RVEDP $(\mathrm{mm} \mathrm{Hg})$ & $7.3 \pm 2.9$ & $5.6 \pm 3.2$ & 0.05 \\
LVEDP $(\mathrm{mm} \mathrm{Hg})$ & $13.3 \pm 5.3$ & $15.0 \pm 6.2$ & NS \\
CI $\left(\mathrm{L} \cdot \mathrm{min}^{-1} \cdot \mathrm{m}^{-2}\right)$ & $3.4 \pm 0.7$ & $3.5 \pm 1.0$ & NS \\
\hline
\end{tabular}

$R A$, Right atrial; $R V E D P$, right ventricular end-diastolic pressure; $L V E D P$, left ventricular end-diastolic pressure; $C I$, cardiac index. $N S$, Not significant.

superior vena caval flow pattern. This pattern consisted of similar forward systolic and diastolic flows in patients who underwent transplantation by the new technique, whereas diminished forward systolic flow was seen in patients who underwent transplantation by the standard technique. Abolished or diminished forward systolic vena caval flow has also been described in restrictive cardiomyopathy. ${ }^{17}$ Ventricular restrictive physiology has been found in acute heart transplant rejection, ${ }^{18}$ and this pattern of diminished or abolished forward systolic vena caval flow has even been proposed as an accurate sign of acute rejection. Other studies have described right and left ventricular restrictive physiology in cardiac transplant recipients with a high rate of rejection. ${ }^{12}$ The same superior vena caval flow pattern could probably be observed in patients after long-term heart transplantation with several previous rejection episodes. Nevertheless, all studies in our patients were performed during the first year after transplantation, with no acute rejection episodes. The number of previous rejection episodes was similar for both groups, and studies in which more than mild tricuspid regurgitation was found were excluded from analysis.

The cause of the difference between groups with respect to vena caval forward flow must be the differences in right atrial size and performance. An increased late diastolic tricuspid flow in patients who underwent transplantation by the new technique means a more vigorous atrial contraction. This was followed by better atrium relaxation, with increased forward vena caval flow during subsequent ventricular systole.

In contrast, right atrial contraction may have been less vigorous in patients who underwent transplantation by the standard technique as a result of atrial sutures and greater atrial size. The diminished atrial contraction and delivery of flow produced lower systolic right atrial filling in the next cycle. In this case, 

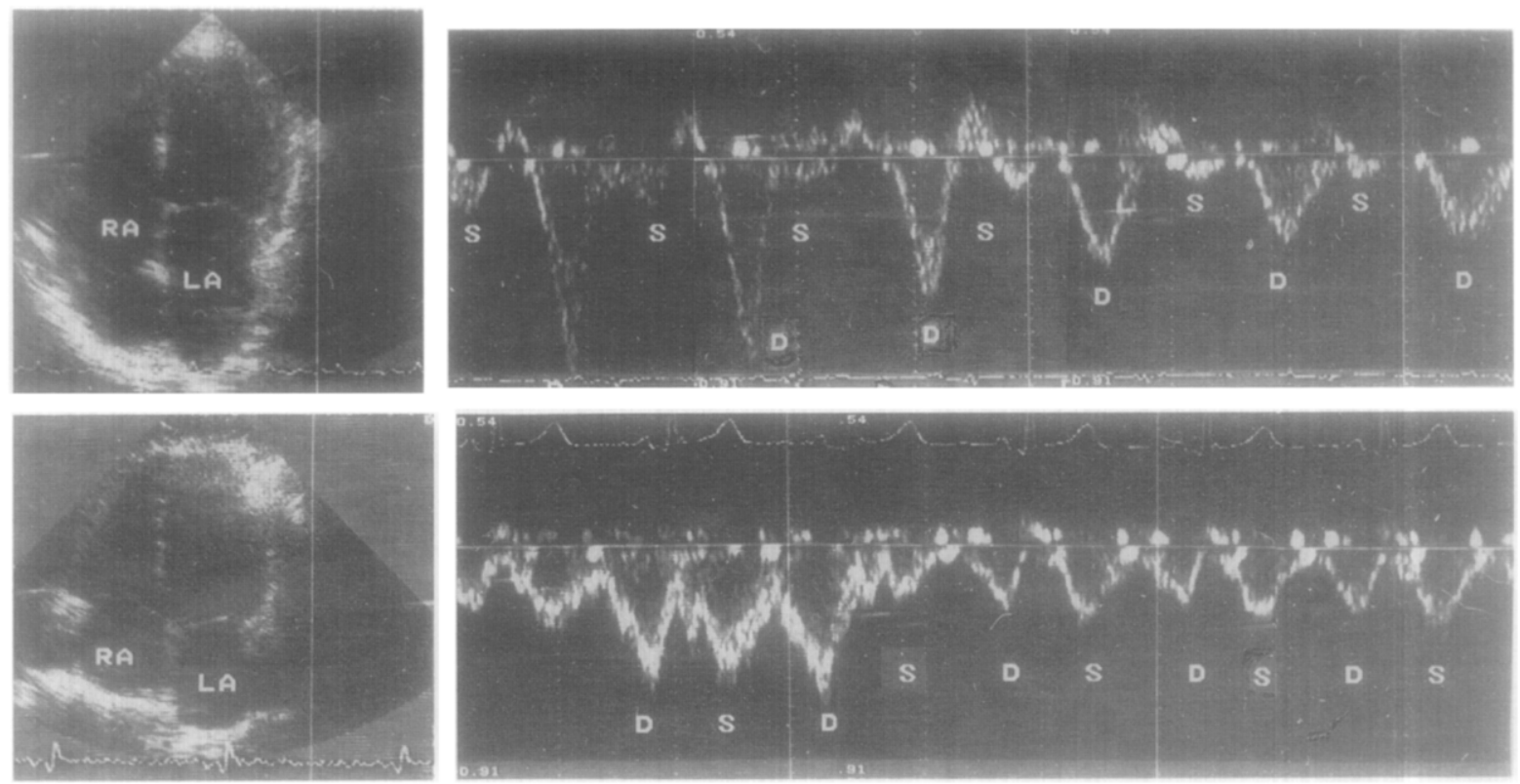

Fig. 2. Two-dimensional echocardiography from the apical view (left) and superior vena caval Doppler pulsed-flow patterns (right) in patients who underwent transplantation by standard (top) or new technique (bottom). Top left, Note increased left and right atrial size in patient who underwent transplantation by standard technique. Bottom left, Nearly normal left and right atrial size in patient who underwent transplantation by new technique. Top right, Diminished superior vena caval systolic flow from inspiration to expiration in patient who underwent transplantation by standard technique. Bottom right, Nearly normal superior vena caval systolic flow from inspiration to expiration in patient who underwent transplantation by new technique.

the right atrial filling was moreover produced in diastole, when the atrium seems to function as a conduit. ${ }^{19}$

Another mechanism proposed for the superior vena caval forward systolic flow is the systolic tricuspid ring displacement. ${ }^{20-21}$ Such a parameter seems to have less importance with regard to the systolic right atrial filling in these cardiac allograft recipients, however, because significant correlations between tricuspid ring systolic displacement and superior vena caval forward systolic flow were not found in this study. Compared with values in healthy subjects, tricuspid ring systolic displacement was decreased similarly in both groups of patients. The mean ( \pm standard deviation) tricuspid ring systolic motion was $16.3 \pm 0.6 \mathrm{~mm}$ in 10 young, healthy adult subjects studied by Kaul and coworkers ${ }^{9}$ and $21.9 \pm 3.4 \mathrm{~mm}$ in 26 patients studied by Wranne and associate ${ }^{20}$ before heart operation. In our overall patient group, mean tricuspid ring systolic motion was $13.6 \pm 3.1 \mathrm{~mm}$, which correlates with a right ventricular ejection fraction of $35 \% \pm 8 \%$ according to the data of Kaul and coworkers ${ }^{9}$, whereas mean ( \pm standard deviation) right ventricular ejection fraction in the healthy subjects was $43 \% \pm 2 \%$ (as measured by radionuclide angiography). The slightly reduced right ventricular anteroposterior systolic shortening seen in our patients could explain the fact that vena caval forward systolic flow depends more on atrial relaxation than on tricuspid ring systolic motion. The lack of increase of tricuspid systolic ring motion in our overall group during follow-up suggests that right ventricular function does not improve significantly during the first year after transplantation.

The findings of reduced left and right ventricular isovolumic relaxation times in patients who underwent transplantation by the new technique probably indicate better relaxation, because right atrial and right ventricular end-diastolic pressures were lower in patients who underwent transplantation by the new technique. Pathologic causes of ventricular isovolumic relaxation time shortening are high atrial pressures or ventricular outflow tract obstruction.

The study of Sarsam and colleagues ${ }^{3}$ also showed lower mean right atrial pressures in patients who underwent transplantation by the new technique, with no differences in pulmonary capillary wedge pressures and cardiac index compared with patients who underwent transplantation by the standard technique. Prevalence of postoperative right ventric- 
ular failure was also lower with the new technique. Nevertheless, equalization of right heart pressures was seen at 6 months.

High $\mathrm{V}$ waves in patients who underwent transplantation by the standard technique may indicate decreased right atrial compliance or decreased right ventricular function, with the former being the dominant factor. The higher $\mathrm{A}$ waves in these patients may reflect an ineffective right atrial attempt to increase flow during late diastole. In fact, this atrium seems to be capable of increasing pressure but not flow.

The reduced right and left atrial sizes, lower right heart filling pressures, and nearly normal superior vena caval flows seen in the group who underwent transplantation by the new technique indicate that the new technique more nearly approximates healthy physiology. Whether these findings imply better exercise tolerance, reduced rate of right heart postoperative failure, or better long-term prognosis remains to be investigated. Moreover, nearly normal right and left atrial size and performance may mean a lower prevalence of atrial thrombus formation and embolism, avoiding the need for anticoagulation that has been found to be advisable by others. ${ }^{22}$ Abolished or diminished forward systolic vena caval flow has been proposed as an accurate index of acute cardiac rejection. ${ }^{18}$ Such index should be reconsidered according to the technique performed, and right atrial size should be taken into account.

\section{REFERENCES}

1. Lower RR, Shumway NE. Studies of the orthotopic homotransplantation of the canine heart. Surg Forum 1960;11:1823.

2. Shumway NE, Lower RR, Stofer RC. Transplantation of the heart. Adv Surg 1966;2:265-84.

3. Sarsam MA, Campbell CS, Yonan NA, Deiraniya AK, Rahman AN. An alternative surgical technique in orthotopic cardiac transplantation. J Card Surg 1993;8:344-9.

4. El Gamel A, Yonan NA, Grant S, Deiranya AK, Rahman AN, Sarsam MA, et al. Orthotopic cardiac transplantation: a comparison of standard and bicaval Wythenshawe techniques. J Thorac Cardiovasc Surg 1995;109:721-30.

5. Deleuze PH, Benvenuti C, Mazzucotelli P, Perdrix C, Le Bernarais $\mathrm{P}$, Mourtada A, et al. Orthotopic cardiac transplantation with direct caval anastomosis: is it the optimal procedure? J Thorac Cardiovasc Surg 1995;109:731-7.

6. Sievers HH, Leyh R, Jahnke A, Petry A, Kraatz EG, Herrmann $\mathrm{G}$, et al. Bicaval versus atrial anastomoses in cardiac transplantation: right atrial dimension and tricuspid valve function at rest and during exercise up to thirty-six months after transplantation. J Thorac Cardiovasc Surg 1994;108:780-4.

7. Billingham ME, Cary NR, Hammond ME, Kemnitz J, Marboe $\mathrm{C}$, McCallister $\mathrm{HA}$, et al. A working formulation for the standardization of nomenclature in the diagnosis of heart and lung rejection: Heart Rejection Study Group. J Heart Transplant 1990;9:587-93

8. Sahn DS, De Maria A, Kisslo J, Weyman A. The Committee on M-mode Standardization of the American Society of Echocardiography: recommendation regarding quantitation in M-mode echocardiography-results of a survey of echocardiographic measurements. Circulation 1978;58:1072-90.

9. Kaul S, Tei Ch, Hopkins J, Shah PM. Assessment of right ventricular function using two-dimensional echocardiography. Am Heart J 1984;107:526-31.

10. Valantine HA, Appleton CP, Hatle LK, Hunt SA, Stinson EB, Popp RL. Influence of recipient atrial contraction on left ventricular filling dynamics of the transplanted heart assessed by Doppler echocardiography. Am J Cardiol 1987;59:1159-63.

11. Triposkiadis F, Starling RC, Hass GJ, Sparks E, Myerowitz PD, Boudoulas $\mathrm{H}$. Timing of recipient atrial contraction: a major determinant of transmitral diastolic flow in orthotopic cardiac transplantation. Am Heart J 1993;126:117581.

12. Valantine HA, Appleton CP, Hatle LK, Hunt SA, Billingham ME, Shumway NE, et al. A hemodynamic and Doppler echocardiographic study of ventricular function in long-term cardiac allograft recipients: etiology and prognosis of restrictive-constrictive physiology. Circulation 1989;79:66-75.

13. Currie PJ, Seward JB, Chan KL, Fyfe DA, Hagler DJ, Mair $\mathrm{DD}$, et al. Continuous wave Doppler determination of right ventricular pressure: a simultaneous Doppler-catheterization study in 127 patients. J Am Coll Cardiol 1985; 6:750-6.

14. Skajaerpe T, Hegrenaes L, Hatle LK. Noninvasive assessment of valve area in patients with aortic stenosis by Doppler ultrasound and two-dimensional echocardiography. Circulation 1985;72:810-8.

15. Appleton CP, Hatle LK, Popp RL. Superior vena cava and hepatic vein Doppler echocardiography in healthy adults. J Am Coll Cardiol 1987;10:1032-9.

16. Appleton CP, Hatle LK, Popp RL. Demonstration of restrictive physiology by Doppler echocardiography. J Am Coll Cardiol 1988;11:757-68.

17. Hatle LK, Appleton CP, Popp RL. Differentiation of constrictive pericarditis and restrictive cardiomyopathy by Doppler echocardiography. Circulation 1989;79:357-70.

18. Simmonds MB, Lythall DA, Slorach C, Ilstey CD, Mitchell $\mathrm{AG}$, Yacoub MH. Doppler examination of superior vena caval flow for the detection of acute cardiac rejection. Circulation 1992;86(Suppl 2):259-66.

19. Nishimura RA, Abel MD, Hatle LK, Tajik AJ. Relationship of pulmonary vein to mitral velocities by transesophageal Doppler echocardiography: effect of different loading conditions. Circulation 1990;81:1488-97.

20. Wranne B, Pinto FJ, Hammarström E, St Goar FG, Puryear J, Popp RL, et al. Abnormal right heart filling after cardiac surgery: time course and mechanisms. Br Heart J 1991;66: $435-42$.

21. Sivaciyan V, Ranganathan N. Transcutaneous Doppler jugular venous flow velocity recording: clinical and hemodynamic correlates. Circulation 1978;57:930-9.

22. Angerman CE, Spes CH, Tammen A, Stempfle HU, Schultz A, Kemkes BM, et al. Anatomic characteristics and valvular function of the transplanted heart: transthoracic versus Transesophageal Echocardiographic findings. J Heart Transplant 1990;9:331-8. 